\title{
On the Role of Age of Onset and Input in Early Child Bilingualism in Greek and Dutch
}

\author{
Sharon Unsworth ${ }^{1,2}$, Froso Argyri ${ }^{3}$, Leonie Cornips ${ }^{2}$, Aafke Hulk ${ }^{4}$, \\ Antonella Sorace $^{3}$, and Ianthi Tsimpli ${ }^{5}$ \\ ${ }^{1}$ Utrecht University, ${ }^{2}$ Meertens Institute, ${ }^{3}$ University of Edinburgh, ${ }^{4}$ University of Amsterdam, \\ and ${ }^{5}$ Aristotle University of Thessaloniki
}

\section{Introduction}

That language input is necessary in order for acquisition to take place is undisputed; the exact role of input in the language acquisition process, however, remains controversial. More specifically, there is disagreement as to how much input is necessary for acquisition to take place and whether indeed all aspects of language can be acquired from input alone (see Valian, 1999, for an overview). Concerning this first question, data from children exposed to two languages may prove instructive. The first goal of this paper is thus to determine the effect of varying amounts of input on child bilinguals acquisition of grammatical gender. We use the phrase 'child bilingual' as a general term referring to any child who is exposed to two languages in childhood, by which we mean up to and including the age of ten. Clearly, such a group of children is heterogeneous in nature, including children exposed to two languages from birth (i.e., simultaneous bilinguals), as well as those exposed to a second language at some point in early or late childhood (i.e., successive bilinguals). The second goal of this paper is to explore the role of age of onset, that is, to ascertain whether there is an effect of age of onset in the linguistic development of child bilinguals in their acquisition of grammatical gender. Grammatical gender is a suitable property to examine in this context because the cues available in the input differ in the two languages under investigation and because grammatical gender is a domain in which age effects are often observed.

In Section 2, we provide a brief review of the relevant literature on input effects in bilingual acquisition, and in Section 3, we turn to the role of age of onset. The relevant properties of grammatical gender in Dutch and Greek are outlined in Section 4, along with a brief overview of the acquisition facts. Section 5 details the methods used to elicit production data on grammatical gender and to determine the amount of input to which children are exposed. The Dutch data and results are presented in Section 6 and the Greek data and results in Section 7. Finally, Sections 8 and 9 contain the discussion and conclusion, respectively.

\section{Input effects in early child bilingualism}

Children growing up bilingually have to divide their time and thus their linguistic input between two languages. They will thus by definition be exposed to quantitatively less input than their monolingual peers (Paradis \& Genesee, 1996). Despite often significantly less exposure, however, simultaneous bilingual (henceforth 2L1) children have been observed to reach the same developmental milestones as monolingual children and do so by and large within the same timeframe, at least for morphosyntax (see Genesee \& Nicoladis, 2007, for an overview). The relationship between input quantity and linguistic development is thus certainly not linear (Paradis \& Genesee, 1996).

\footnotetext{
* This research was supported by the Netherlands Organisation for Scientific Research with an international programme award to Leonie Cornips and with a VENI Innovational Research Incentives Scheme award to Sharon Unsworth.
} 
Several recent studies have found effects of input quantity on various aspects of the language acquisition of bilingual children. For example, in a series of studies on bilingual English/Spanish children in Miami, Gathercole (2002a, 2002b, 2002c) observed that younger bilingual children with less exposure to the target language at home and/or at school performed systematically more poorly than those with more exposure, including their monolingual peers; the target language phenomena in question were the mass/count distinction in English, that-trace effects in English and Spanish, and grammatical gender in Spanish. Gathercole noted, however, that by the time children reach grade 5 (around age 10), this difference had largely disappeared, leading her to suggest that amount of exposure may play a greater role in the early years, that is until children have reached a critical mass of input with respect to the relevant linguistic property (2002c, p. 247). In a study with the same children, Cobo-Lewis et al. (2002a, 2002b) observed that the vocabulary acquisition is also subject to input effects, in both the minority and majority language (see also Scheele, Leseman, \& Mayo, 2010). Both these and other studies also noted a significant effect of socio-economic status, often measured in terms of level of parental education, both of which may affect the amount and type of input which children are exposed to (e.g., Hoff, 2006, for an overview).

One of the critical questions concerning bilingual language development and input is how much input is enough for language acquisition in two languages to be successful and more in particular, for bilingual children to perform similarly to their monolingual peers. As yet, very few studies address this issue. In a study of 2L1 English/French children in Canada, approximately $40 \%$ exposure to the target language was observed to be enough to score within monolingual norms for MLU and a number of standardised tests, such as the PPVT and CELF (Thordardottir, 2008). Furthermore, in a study of Spanish/English bilingual toddlers, 60\% regular exposure was observed to be enough to achieve processing speed comparable to monolingual peers (Hurtado, Grüter, Marchman, \& Fernald, 2009). In a survey of family language use, De Houwer (2007) found that bilingual children typically experience few problems acquiring the majority language, but in order to successfully acquire the minority language, it is essential that one or both parents provide input in that language in the home. An effect of parental input, that is, whether both or just one parent (in two-parent households) speaks the target language, was also observed by Barreña, Ezeizabarrena, and García (2008). In their study of the early lexical and morphosyntactic development of Spanish/Basque bilingual children, they found that bilingual children with on average $>60 \%$ exposure to Basque at time of testing performed similarly to monolinguals and often significantly better than bilingual children with less exposure (between $30 \%$ and $60 \%$ at time of testing).

To summarize: amount of language exposure has been observed to affect the linguistic development of bilingual children in a variety of domains. The exact nature of the relationship between input quantity and language acquisition in a dual language setting largely remains unclear, however. This is in part due to the complex nature of this setting, which means that input quantity interacts with and is affected by numerous other factors, including input quality, parental education, and socioeconomic status, as well as age of onset. The present study focuses on input quantity and this latter variable of age of onset, to which we now turn.

\section{Age effects in early child bilingualism}

Many of the studies mentioned in the preceding section focus on simultaneous bilingual children. As noted above, the linguistic development of these children by and large follows that of monolingual children, and it is generally assumed that, provided exposure to the languages in question is maintained, they will ultimately attain the same level as their monolingual peers (but see Hyltenstam, 1992; McDonald, 2000; etc.). When it comes to successive bilinguals, children are typically found to outperform adults, which has lead to the postulation of various ages as the end of a critical or sensitive period (see Herschensohn, 2007 for an overview). Most studies of the role of age of onset in second language (L2) acquisition compare L2 children with L2 adults, but more recently, attention has turned to exploring age effects within childhood and comparing early successive and simultaneous bilinguals.

In a study on the acquisition of various aspects of French morphosyntax, Granfeldt, Schlyter, and Kihlstedt (2007) compared three groups of children: monolinguals, 2L1 and L2, where the age of onset for the latter group was between 3 and 6 years and the other language for both bilingual groups was 
Swedish, which was also the language of the environment. They found that, whereas the $2 \mathrm{~L} 1$ children patterned similarly to the monolinguals, the L2 children produced errors typical of L2 adults. Interestingly, in two studies of the acquisition of German word order by Turkish-speaking children, Rothweiler (2006) and Chilla (2008) found slightly different results among children with comparable ages of onset, namely they observed that those children with an age of onset of around 6 years patterned with L2 adults, whereas those with age of onset at 3 years patterned similarly with $2 \mathrm{~L} 1$ and monolingual (L1) children. More recently, Meisel (2009) has suggested that there is a critical period for some aspects of morphosyntax ending at around age 4, and as such, age 4 may be seen as the dividing line between (2)L1 acquisition, on the one hand, and child L2 and adult L2 acquisition, on the other.

To summarize: recent research has examined the development of different types of child bilinguals, as classified in terms of age of onset. The results suggest that there are age effects in early child bilingualism with children exposed to their L2 around age 6 typically producing errors which are different in type from children exposed to the L2 before or around age 3 but similar to those produced by L2 adults. More specifically, it has been proposed (Meisel, 2009) that the age of four constitutes the critical age for some aspects of morphosyntax. The aforementioned studies used spontaneous production data only, and often involved qualitative (i.e., example-based) analyses. Although such studies provide much-needed detail, especially concerning longitudinal development, the limited number of children included in the sample means that the results are not generalizable to the wider bilingual child population. The present paper seeks to test the claim put forward by Meisel (2009) using data on the acquisition of grammatical gender in Dutch, and in Greek, using elicited production data from a larger number of child bilinguals.

\section{4. (The acquisition of) grammatical gender in Dutch and Greek}

Before outlining the specific properties of grammatical gender in the two target languages under consideration, namely Dutch and Greek, let us first consider the previous literature on the effect of input quantity and age of onset on the acquisition of this particular linguistic property. Grammatical gender is often (although not always) observed to be a source of errors for L2 adults (e.g., Franceschina, 2005), and this has often been related to the presence/absence of a grammatical gender feature in the learners' L1 (e.g., Sabourin, Stowe, \& de Haan, 2006). For the children in the present study, the other language is always English; English does not have a grammatical gender feature so if this language affects the acquisition of grammatical gender in Dutch or Greek in the child bilinguals tested here, this effect should in principle be the same for all children.

The results for bilingual children, on the other hand, are mixed. Generally speaking, in their acquisition of grammatical gender, $2 \mathrm{~L} 1$ children have been observed to make the same types of errors as monolinguals (e.g., De Houwer, 1990; Müller, 1990), although they may experience a delay (Kupisch, Müller, \& Cantone, 2002). In the study cited above, Meisel (2009) claims that the gendermarking on determiners produced by children whose age of first exposure to French was 3;7 or later is inconsistent with the generalisations made by (2)L1 children, which are based on the formal properties of the noun. Similarly, Carroll (1989) claims that after age 5, children whose L1 does not have grammatical gender, are unable to acquire this feature in an L2. In contrast, Montrul, Foote, and Perpiñán (2008) presented data from heritage speakers of Spanish showing that despite exposure to the language from birth, these learners still make similar errors to adult L2 learners. These authors suggested that this non-target-like performance was due to variable and insufficient input.

Gathercole (2002b) also observed input effects in the acquisition of grammatical gender in Spanish. She found that grade 2 children (around age 6), with the greatest amount of input at home and at school (i.e., children with Spanish-speaking parents attending bilingual schools), were better at rejecting incongruent determiner-noun combinations than grade 2 children with less input (i.e., with English spoken at home in English immersion programmes), and that the children with the least input took the longest to acquire these forms. Similarly, in a study of the acquisition of the grammatical gender system in Welsh, Gathercole and Thomas (2005) found more target-like production and comprehension for children with the most exposure to Welsh at home and/or at school, with exposure at home having a greater influence on results than exposure at school. Furthermore, the authors 
observed that the extent of such input effects in part depends on the relative complexity and/or idiosyncrasy of the particular aspect of the gender system in question, with the more complex or opaque forms requiring more input. More specifically, they claim that multiple form-function pairings "appear to lend opacity and to make acquisition more difficult" (Gathercole \& Thomas, 2005, p. 871). Interestingly, they also speculate that the more opaque and complex structures may be timed off the map' in the sense that children who do not receive enough relevant input in the early years may never come to completely acquire the target language property in question. In other words, what is at work here is a complex interplay between age of onset and input quantity, an issue to which we return below.

The two target languages under investigation here are Dutch and Greek. Dutch has a two-way gender system, distinguishing between common and neuter; this distinction is marked on definite and demonstrative determiners, relative pronouns and attributive adjectives. The focus of the present study is on definite determiners only. Common nouns take the definite determiner de, as in de muis 'the mouse', whereas neuter nouns are preceded with het, as in het huis 'the house'. All plural DPs take de and there is no gender-marking on indefinite determiners; furthermore, common nouns are much more frequent than neuter nouns (Van Berkum, 1996). There are some morphological and semantic regularities but these are limited and there are many exceptions (Donaldson, 1987; Haeseryn, 1997).

When it comes to the acquisition of grammatical gender in Dutch, monolingual, 2L1 and L2 children overgeneralize the common determiner $d e$ with neuter nouns, producing non-target DPs of the

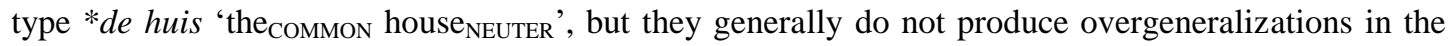
other direction. Monolingual children make these errors until at least age six (Blom, Polišenskà, \& Weerman, 2008; van der Velde, 2003). 2L1/L2 children ${ }^{1}$ have been found to continue to make such errors beyond this age (Blom et al., 2008; Hulk \& Cornips, 2006; Unsworth, 2008), and various factors have been cited to account for this observation, including the sociolinguistic context involved, as well as the quantity and quality of the input to which children are exposed (Cornips \& Hulk, 2008; Unsworth, 2008).

Greek is a grammatical gender language with a tripartite gender distinction: masculine-feminineneuter. This distinction is marked on definite determiners in both the singular and the plural, on indefinite articles, as well as on adjectives. Gender marking on the noun follows certain phonological regularities (e.g., in the citation form an $-s$ ending usually marks masculine, whereas $-a$ and $-o$ mark feminine and neuter respectively). More specifically, Greek nouns are suffixed by a syncretic form which includes gender, number, and case information. With respect to gender marking, Mastropavlou and Tsimpli (2011) show that despite the possibility of some of these endings such as $-o s$ and $-i$ occurring with more than one gender feature (e.g., -os could be masculine, feminine or neuter while $-i$ could be feminine or neuter), predictive values are very high for one of these values, ranging from .84 to .98 . The only exception is the ending $-i$ which is indeed ambiguous between feminine and neuter (in spoken language only). An example, showing gender agreement between the article, the adjective, and a (masculine) noun ending in $-o s$ is given in (1).

(1) $\mathrm{O}$ oreos kipos.

the-masc beautiful-masc garden-masc

'The beautiful garden'

Studies of the monolingual acquisition of Greek show that gender agreement is acquired by around age 3;6 to 4;0 (Tsimpli, 2004). Neuter is considered the unmarked gender and has been proposed to bear the default function (see Mastropavlou, 2006). This proposal is supported by research that shows that neuter is the easiest to acquire by young children during the early stages of acquisition (see Stephany, 1995) and it is also the most overused gender in the production of second language learners of Greek (Tsimpli, 2004; Varlokosta, 1995). Mastropavlou (2006) found that in the early developmental stages, young Greek children overused neuter forms inappropriately more often than older Greek children.

1 The exact age of onset for the children in the cited studies is difficult to establish (Cornips \& Hulk, 2008). 
Comparing the two systems, we see that Greek has systematic and largely unambiguous gendermarking on all elements within the DP, but this is not the case for Dutch, where gender-marking on the noun is largely absent and on other DP elements, it is often inconsistent or ambiguous. Thus, whereas gender-marking in Greek might be considered to be relatively transparent, in Dutch, it is rather opaque.

Having outlined the relevant properties of gender in the two target languages, we now turn to our research questions in order to make specific predictions for the learner populations under investigation here. Our first research question asks what the effect is of varying amounts of input for the development of grammatical gender as marked on definite determiners in English/Dutch and English/Greek child bilinguals. For Dutch, the available cues for neuter gender are limited. As noted above, gender-marking is restricted to certain types of determiner and pronouns only, morphological and semantic regularities are limited, and the definite determiner used with singular common nouns, $d e$, is also used for plural nouns of both genders. Furthermore, the lexical form, het, the definite determiner used with neuter nouns, also serves other functions (e.g., as a pronominal form), in impersonal constructions, with nominalised infinitives and with predicative superlatives (Hulk \& Roodenburg, 2008). According to Gathercole and Thomas (2005), this means that this form is more opaque and consequently, it should require more input than a less opaque form for acquisition to take place. Given the lack of systematic cues, the specification of gender in Dutch, and of neuter nouns in particular, must to a certain extent occur on a word-by-word basis (Carroll, 1989; Unsworth, 2008). If this is the case, it is expected that that input quantity should affect the acquisition of grammatical gender in Dutch. This contrasts with Greek. In this language, the cues for gender are abundant and transparent: gender is consistently marked on both the noun and any agreeing DP constituents. Arguably, this means that input to the language-learning child in Greek should provide enough cues for target-like acquisition of grammatical gender to take place. Thus, our first hypothesis is that input effects will be observed for English/Dutch bilingual children but only to a limited extent (if at all) in Greek. More specifically, we expect amount of exposure, as measured by an extensive parental questionnaire on the children's language use and background, to have a greater effect on the acquisition of grammatical gender in Dutch than on the acquisition of grammatical gender in Greek.

Our second research question concerns the existence of age effects in early child bilingualism. More specifically, we hypothesise that if the proposal put forward by Meisel (2009) is correct, namely that there is a critical period for some aspects of morphosyntax ending at around age 4, then the linguistic development of bilingual children whose age of first exposure is age 4 or older should be different from bilingual children whose age of first exposure is less than 4. For example, as suggested by Meisel for the acquisition of grammatical gender in French by German/French bilinguals, we would expect children with an age of onset of 4 years or older to produce different types of errors from children with a younger age of onset.

\section{Method}

Children's knowledge of grammatical gender-marking on definite determiners was tested using elicited production tasks, two for Dutch and one for Greek. The general set-up of the tasks in both languages was the same, namely: children were presented with pictures of the relevant nouns on a computer screen and first asked to name them, thereby eliciting an indefinite noun. Subsequently, they were asked a question about the same object (e.g., "Which is green?") or prompted to describe the position of another object relative to the object of interest (e.g., ("The ball is in front of ... (child: ... the rabbit)"). More specific details of the Dutch tasks (following Blom et al., 2008 a.o.) can be found in Unsworth and Hulk (2009). The Greek task is based on Mastropavlou's (2006) work on gender acquisition in L1 Greek. The maximum number of items per gender was 18 for Greek, and for Dutch, 21 for younger children ( $\leq 5$ years at time of testing) and 27 for older children ( $>6$ years). In Greek, six different endings were used: $-a s$ and $-o s$ for masculine nouns, $-a$ and $-i$ for feminine nouns, and $-o$ and $-i$ for neuter nouns. All have high predictive values with, as noted above, the exception of $-i$. In both languages, test items, interspersed with fillers, were presented in two orders, B being the reverse of A, counter-balanced across children. The results for the two tasks are presented for each language separately below. 
In addition to the gender tasks, children were also tested using standardised vocabulary tests: the Peabody Picture Vocabulary Test (PPVT-4) (L. M. Dunn \& Dunn, 2007) or the British Picture Vocabulary Scale (BPVS) (L. M. Dunn, Dunn, Whetton, \& Burley, 1997) for English, depending on the variety to which children were exposed, the PPVT-III-NL (L. M. Dunn, Dunn, \& Schlichting, 2005) for Dutch and the DVIQ (Diagnostic Verbal IQ - vocabulary section) test for Greek (Stavrakaki $\&$ Tsimpli, 2000). The results of these tasks are used as a general indicator of the children's relative proficiency in the two languages.

An extensive parental questionnaire on children's language use and background (partly based on Gathercole, p.c.; Gutiérrez-Clellen \& Kreiter, 2003; Jia \& Aaronson, 2003; Paradis, Emmerzael, \& Duncan, 2010) was used in order to estimate input quantity. ${ }^{2}$ Parents were asked to indicate who spent time with the child during an average day in the week and at the weekend, how much time this was and the amount of Dutch or Greek (as opposed to English) each person used when addressing the child. They were also asked to indicate the amount of time spent at daycare, school and out-of-school care (depending on the child's age) and about the number of hours per week spent on other activities, including reading, clubs and sports, watching TV, using computers and the internet, as well as time spent with friends, and for each of these, the proportion of time each of the two languages were used. This was included in the analysis as the percentage of weekly language exposure in the target language.

Perhaps more important than the children's current language exposure was how much target language exposure they had had over time, or rather, their length of exposure. Traditionally, length of exposure in L2 acquisition studies is operationalized as the learner's chronological age (i.e., age at time of testing) minus their age of onset. Thus, for example, a child who is tested at 7 years of age and who was first exposed to the target language at 3 years of age is said to have in total 4 years' exposure. Clearly, given that bilingual children have to divide their language exposure time between two languages, these 4 years of exposure are quantitatively incomparable to the amount of exposure which a monolingual child will receive in the same period. Furthermore, as the results of our questionnaire demonstrate, the amount of exposure which bilingual children receive varies greatly. To give an example, the results of the calculation outlined in the previous paragraph for the $332 \mathrm{~L} 1$ children tested in the Dutch part of this study ranged from between $19 \%$ and $79 \%$ exposure to Dutch on a weekly basis. In order to capture the extent of this variation when it comes to measuring language exposure over time, we have tried to develop a new measure, which we dub cumulative length of exposure (see Gutiérrez-Clellen \& Kreiter, 2003, for a similar approach).

In brief (see Unsworth, 2011; Unsworth, under review, for more details), this measure works as follows. The questionnaire contained the following information for each child: (i) how much each parent and any other adults living in the home spoke the two languages (English and Dutch/Greek) for each one- or two-year period in the child's life to that point, using a 5-point scale, which ranges from "almost always English" to "almost always Dutch/Greek"; (ii) whether the child attended daycare or school in these periods, and if so, what the language of instruction was there, using the same 5-point scale. From this, we were able to estimate how much each child was exposed to the target language at home by averaging the scores in (i) for each period. Each point on the scale was counted as $0 \%, 25 \%$, $50 \%, 75 \%$ or $100 \%$, respectively. We then estimated how much time each child spent on average at daycare and/or school for each year in his or her life to the time of testing. The rest of the year was considered as time at home. The denominator in these calculations is the average number of waking hours per year, which we calculated based on the average number of hours which young children sleep and for the older children on data about waking hours gleaned from the questionnaire data.

To estimate how much exposure a child had to the target language in a given year, we made the following calculation: (average \% exposure to Dutch/Greek in the home x number of hours per year at home $)+$ (average \% exposure to Dutch/Greek at daycare/school x number of hours per year at daycare/school) / total number of waking hours in year. This results in the average proportion of target language exposure during that year. Subsequently, to estimate cumulative length of exposure, the results of this calculation for each one or two-year period (or part thereof) in the child's life were

2 Information was also collected about input quality but this is not reported here. 
totalled. For example, say a child in a given period spent $75 \%$ of the year at home and $25 \%$ at daycare, the mother almost always spoke English, the father half English/half Dutch, and the daycare was in Dutch. If this were for example the period between 2 and 3 years, then based on the estimates mentioned above, the total number of waking hours per year was 4160, of which 1040 was spent at daycare. Thus, the calculation would be as follows: $((0+.5) / 2) \times 3120)+(1 \times 1040) / 4160$, which translates as $(780+1040) / 4160$, which equals 0.43 . What this means is that we estimate that $46 \%$ of the weekly language exposure in this particular year of the child's life was in Dutch. Clearly, this estimation is only as good as the report data on which it was based; there are, however, studies indicating that parental report is a reliable and valid means of collecting data concerning children's (language and language-related) behaviour (e.g., Marchman, Martinez-Sussman, \& Dale, 2004; Rodriguez et al., 2009), and that the child's age does not necessarily adversely affect retrospective parental report (Gilger, 1992; see also Paradis et al., 2010). We therefore hope that cumulative length of exposure, while of course still only an overall estimation, will at least provide a more precise indication of a learner's exposure to the target language over time than its traditional counterpart, and as such, will facilitate better differentiation between children and thus hopefully, more accurate results (Unsworth, 2011).

\section{Dutch data}

The children were divided into three groups, based on their age of onset, namely $2 \mathrm{~L} 1$ (i.e., exposure to both languages from birth), L2 children (i.e., exposure to Dutch between the ages of 4 and 10), and finally, the as yet largely under-researched group of early successive bilinguals (i.e., children who are exposed to English from birth and Dutch after age 1 but before age 4) sometimes referred to as early cL2. All children were resident in The Netherlands; most attended Dutch-speaking primary schools, but some attended international schools, where English is the main language of instruction. All the children in the $2 \mathrm{~L} 1$ group were in principle raised using Grammontian principle of 'one parent, one language', although some parents used both languages with the children at the time of testing. An overview of the biodata for the Dutch participants, as well as the two measures based on the questionnaire and the results of the vocabulary tasks, is given in Table 1. Data were also collected from 30 monolingual Dutch 4 to 6 year olds $(M 5 ; 9, S D$ 0;11). Their average score on the PPVT-NL vocabulary task was 109 (SD 10.3).

Table 1

Overview of biodata for English/Dutch children

\begin{tabular}{|c|c|c|c|c|c|c|c|}
\hline Group & $\mathrm{N}$ & $\begin{array}{c}\text { Age of } \\
\text { onset }\end{array}$ & $\begin{array}{l}\text { Age at } \\
\text { testing }\end{array}$ & $\begin{array}{l}\text { Length of } \\
\text { exposure } \\
\text { (traditional) }\end{array}$ & $\begin{array}{l}\text { Length of } \\
\text { exposure } \\
\text { (cumulative) }\end{array}$ & $\begin{array}{c}\% \\
\text { exposure } \\
\text { to } \mathrm{NL} \\
\end{array}$ & $\begin{array}{c}\text { PPVT- } \\
\text { NL }\end{array}$ \\
\hline $2 \mathrm{~L} 1$ & 56 & 0 & $\begin{array}{c}5 ; 11 \\
4 ; 0-7 ; 9 \\
S D 1 ; 2\end{array}$ & $\begin{array}{c}5 ; 11 \\
4 ; 0-7 ; 9 \\
S D 1 ; 2\end{array}$ & $\begin{array}{c}3 ; 3 \\
0 ; 11-5 ; 9 \\
S D 1 ; 0\end{array}$ & $\begin{array}{c}59 \\
8-81 \\
S D 17\end{array}$ & $\begin{array}{c}109 \\
78-132 \\
S D 13\end{array}$ \\
\hline $\begin{array}{l}\text { Early } \\
\text { successive } \\
\text { bilinguals }\end{array}$ & 37 & $\begin{array}{c}2 ; 4 \\
1 ; 0-3 ; 10 \\
S D 0 ; 9\end{array}$ & $\begin{array}{c}7 ; 6 \\
3 ; 4-17 ; 0 \\
S D 3 ; 3\end{array}$ & $\begin{array}{c}5 ; 2 \\
0 ; 7-15 ; 0 \\
S D 3 ; 6\end{array}$ & $\begin{array}{c}1 ; 8 \\
0-6 ; 6 \\
S D 1 ; 7\end{array}$ & $\begin{array}{c}39 \\
0-86 \\
S D 21\end{array}$ & $\begin{array}{c}94 \\
55-127 \\
S D 17\end{array}$ \\
\hline $\begin{array}{l}\text { L2 } \\
\text { children }\end{array}$ & 53 & $\begin{array}{c}6 ; 5 \\
4 ; 0-10 ; 11 \\
S D 2 ; 1\end{array}$ & $\begin{array}{c}9 ; 10 \\
5 ; 11-16 ; 2 \\
S D 2 ; 2\end{array}$ & $\begin{array}{c}3 ; 5 \\
0 ; 6-9 ; 5 \\
S D 2 ; 3 \\
\end{array}$ & $\begin{array}{c}0 ; 8 \\
0-4 ; 4 \\
S D 0 ; 11 \\
\end{array}$ & $\begin{array}{c}24 \\
0-76 \\
S D 21 \\
\end{array}$ & $\begin{array}{c}91 \\
54-131 \\
S D 21 \\
\end{array}$ \\
\hline
\end{tabular}

As noted above, there was considerable variation in the amount of exposure to Dutch both within and across groups at testing. As might be expected, children in the L2 group, where English was the 
home language, had considerably less exposure to Dutch than those in the other two groups. ${ }^{3}$ This variation is also reflected in the scores for cumulative length of exposure: the difference between this and the traditional measure is greatest for the L2 children.

The children's responses on the gender tasks were analysed as follows: for each child, the average percentage of nouns with target determiner was calculated by dividing the number of nouns produced with the target definite determiner (de for common nouns or het for neuter nouns) by the total number of nouns of the same gender produced with either of these determiners. The average number of items produced with definite determiners by younger ( $\leq 5$ years) children was 17.5 for common Ns and 15.6 for neuter Ns (max. 21), and by older (> 6 years) children, 24.5 for common Ns and 23.2 for neuter Ns (max. 27). The group results for both common and neuter nouns are given in Table 2.

Table 2

Dutch: average percentage of Ns produced with target determiner.

\begin{tabular}{c|ccc}
\hline Group & $\mathrm{N}$ & Common & Neuter \\
\hline \multirow{2}{*}{ L1 children } & \multirow{3}{*}{30} & 96.9 & 51.7 \\
& & $S D 12$ & $S D 34$ \\
2L1 children & 56 & 97.7 & 36.3 \\
& & $S D 5$ & $S D 38$ \\
Early successive bilinguals & \multirow{3}{*}{37} & 95.5 & 22.2 \\
& & $S D 10$ & $S D 33$ \\
L2 children & 53 & 96.4 & 19.4 \\
& & $S D 13$ & $S D 34$ \\
\hline
\end{tabular}

There is a significant difference between common and neuter Ns for L1 $(t(29)=-6.3, p<.001)$, $2 \mathrm{~L} 1(t(55)=-11.6, p<.001), \operatorname{ESB}(t(36)=-11.4, p<.001)$ and L2 children $(t(52)=-14.0, p<.001)$, meaning that all children perform significantly better on common nouns than on neuter nouns. The SDs indicate considerably more variation for neuter nouns than for common nouns for all groups. Between-group comparisons reveal a significant effect for neuter nouns $(F(3,171)=6.69, p<.001)$ but not for common nouns $(\mathrm{F}(2,171)=.40, \mathrm{p}>.05)$. Post-hoc (Tukey) analyses show significant differences between L1 and ESB children $(M D=29.5, p<.01)$, and between L1 and L2 children (MD $=32.3, p<.01$ ), but not between any other groups.

Simple bivariate correlations between the dependent and independent variables were carried out and whenever significant correlations were observed, the independent variables, were entered into a backward-elimination regression analysis for bilingual participants only (following the approach in Jia, Aaronson, \& Wu, 2002). ${ }^{4}$ In the Dutch data, this was the case for all independent variables, that is, age of onset, chronological age (i.e., age at testing), traditional length of exposure, cumulative length of exposure, \% exposure to Dutch, and vocabulary score in Dutch (PPVT-III-NL). In the resulting model (adjusted $\left.R^{2}=.55, \mathrm{p}<.001\right)$, age of onset and traditional length of exposure were removed, cumulative length of exposure $(\beta=.45, \mathrm{p}<.001)$, chronological age $(\beta=.35, \mathrm{p}<.001)$ and vocabulary score $(\beta=$ $.22, \mathrm{p}<.01)$ were found to be significant predictor variables, and $\%$ exposure to Dutch was approaching significance $(\beta=.17, \mathrm{p}=.07)$.

In order to further examine the role of age of onset and cumulative length of exposure, children from each group were - insofar as possible - matched on the basis of this latter variable. The biodata (see Table 1) shows that the three groups of bilingual children differ significantly from each other in terms of cumulative length of exposure. This is in part due to the sample and in part due to inevitable group characteristics. By definition, L2 children are not exposed to the target language during the first

3 Children who have $0 \%$ exposure to Dutch or 0 cumulative years of exposure were children who speak English only at home, who attended an English-speaking school and whose only contact with Dutch was during a onehour class every week and from ambient language exposure (i.e., in shops or on street signs, etc).

4 Our main motivation for using a backward-elimination procedure was the multicollinearity observed in the Greek data (see below); in order to keep the analyses as comparable as possible, the same method was adopted for the Dutch data. 
four years of life and after this point, exposure typically only takes place outside the home; this seriously reduces the amount of input they will hear and thus their cumulative length of exposure, when compared with, for example, $2 \mathrm{~L} 1$ children. The differences between the three groups of bilingual children in the present study are perhaps more extreme than they might be in other cases, however; this is because there are several L2 children whose only exposure to Dutch was during a weekly class at an otherwise English-speaking international school (cf. fn. 3). While a shorter (cumulative) length of exposure is, for the reasons just given, in part inevitable for L2 children, in other linguistic and social settings, the differences between the various groups of bilingual children may be less pronounced, for example for immigrant children whose L1 exposure is restricted to the home only.

The relatively low values for cumulative length of exposure for the early successive bilinguals $(M$ $=1 ; 7)$ and the L2 children $(M=0 ; 8)$ mean that it is virtually impossible to find $2 \mathrm{~L} 1$ children with comparable cumulative lengths of exposure. If $2 \mathrm{~L} 1$ children are on average exposed to Dutch $59 \%$ of the time, they will be age 2 to 3 years old when their cumulative length of exposure is comparable to the other two groups, and at this age, they will be too young to test using the methods employed here. It is, however, possible to compare a subset of the ESB and L2 children. The majority (82\%) of the L2 children had had between 0 and 1 years' cumulative exposure to Dutch. If we compare these children $(n=41)$ with the ESB children $(n=17)$ who also fall within this range, we find that they produced the target-like determiner het with neuter nouns at a very similar rate: $6.3 \%(S D 12.5)$ for the ESB children and $8.1 \%$ ( $S D$ 18.6) for L2 children. There is no significant difference between the two $(t(56)=-.36, p$ $>.05)$. The only $2 \mathrm{~L} 1$ child to fall within this range, with a cumulative length of exposure of $0 ; 11$, scored $0 \%$, and the ten $2 \mathrm{~L} 1$ children in the sample with the lowest cumulative length of exposure $(0 ; 11$ $-2 ; 1)$ scored on average $1.5 \%$ for production of het.

To summarize: whereas children's performance on common nouns was at ceiling, performance on neuter Ns was poor across all three groups. There was considerably more within-group variation with neuter nouns than common nouns. At first sight, the between-group comparisons suggest an age effect, with L2 children producing on average fewer target definite determiners with neuter nouns than the 2L1 children. However, closer analysis of the biodata of these children reveals a confound between age of onset and (cumulative) length of exposure. A regression analysis shows it is in fact cumulative LoE, and to a lesser extent chronological age and vocabulary score, which best predict performance on neuter nouns, with \% exposure to Dutch, an almost significant predictor variable; taken together, these variables account for about half of the variance observed in the data for neuter nouns.

\section{Greek data}

The children were divided into three groups, based on their age of onset, as in Dutch. The 2L1 children were exposed to English and Greek simultaneously from birth or soon afterwards, the L2 children had exposure to Greek from age 4 to 10 years of age, and the early successive bilinguals, are exposed to English from birth and Greek between the ages of 1 and 4. All children were resident in Athens. Many child participants attended Greek-speaking primary schools, but several attended international schools, in which English was the main language of instruction. All the 2L1 children were raised using the 'one parent, one language' strategy. An overview of the biodata for the Greek participants, as well as the two measures based on the questionnaire and the results of the vocabulary tasks, is given in Table 3. Data were also collected from 21 monolingual Greek children aged between $4 ; 0$ to $9 ; 3(M 6 ; 4 ; S D 1 ; 4)$; their average score on the DVIQ vocabulary test was 26.7 (SD 0.6) out of a possible maximum of 27 . 
Table 3

Overview of biodata for English/Greek children

\begin{tabular}{|c|c|c|c|c|c|c|c|}
\hline Group & $\mathrm{N}$ & $\begin{array}{l}\text { Age of } \\
\text { onset }\end{array}$ & $\begin{array}{l}\text { Age at } \\
\text { testing }\end{array}$ & $\begin{array}{l}\text { Length of } \\
\text { exposure } \\
\text { (traditional) }\end{array}$ & $\begin{array}{l}\text { Length of } \\
\text { exposure } \\
\text { (cumulative) }\end{array}$ & $\begin{array}{c}\% \\
\text { exposure } \\
\text { to Greek }\end{array}$ & $\begin{array}{l}\text { DVIQ- } \\
\text { Greek }\end{array}$ \\
\hline 2L1 & 19 & 0 & $\begin{array}{c}5 ; 5 \\
4 ; 2-6 ; 9 \\
S D 0 ; 8\end{array}$ & $\begin{array}{c}5 ; 5 \\
4 ; 2-6 ; 9 \\
S D 0 ; 8\end{array}$ & $\begin{array}{c}3 ; 2 \\
1 ; 8-4 ; 9 \\
S D 0 ; 9\end{array}$ & $\begin{array}{c}42 \\
25-63 \\
S D 12\end{array}$ & $\begin{array}{c}26 \\
24-27 \\
S D 1\end{array}$ \\
\hline $\begin{array}{l}\text { Early } \\
\text { successive } \\
\text { bilinguals }\end{array}$ & 19 & $\begin{array}{c}2 ; 2 \\
1 ; 0-3 ; 4 \\
S D 0 ; 7\end{array}$ & $\begin{array}{c}9 ; 3 \\
5 ; 0-16 ; 0 \\
S D 2 ; 9\end{array}$ & $\begin{array}{c}7 ; 1 \\
3 ; 0-14 ; 0 \\
S D 2 ; 9\end{array}$ & $\begin{array}{c}2 ; 2 \\
0 ; 8-3 ; 9 \\
S D 0 ; 9\end{array}$ & $\begin{array}{c}15 \\
0-25 \\
S D 14\end{array}$ & $\begin{array}{c}21 \\
10-27 \\
S D 5\end{array}$ \\
\hline $\begin{array}{l}\text { L2 } \\
\text { children }\end{array}$ & 19 & $\begin{array}{c}6 ; 4 \\
4 ; 0-10 ; 5 \\
S D 1 ; 9\end{array}$ & $\begin{array}{c}10 ; 9 \\
7 ; 5-16 ; 5 \\
S D 2 ; 2\end{array}$ & $\begin{array}{c}4 ; 5 \\
0 ; 5-9 ; 5 \\
S D 2 ; 3\end{array}$ & $\begin{array}{c}0 ; 9 \\
0-2 ; 9 \\
S D 0 ; 9 \\
\end{array}$ & $\begin{array}{c}8 \\
0-24 \\
S D 7\end{array}$ & $\begin{array}{c}16 \\
6-25 \\
S D 6 \\
\end{array}$ \\
\hline
\end{tabular}

Similarly to the Dutch groups, there was quite some variation in the amount of exposure to Greek both within and across groups, albeit not to quite the same extent as with the Dutch groups. Once again, it was the L2 children who had the lowest exposure scores, but scores on this variable were, for all groups, slightly lower for the English/Greek children than the English/Dutch children. ${ }^{5}$ Conversely, although the English/Greek and the English/Dutch 2L1 children are comparable in terms of traditional length of exposure, the English/Greek ESB and L2 groups have had longer exposure (measured traditionally) than their English/Dutch counterparts. Nevertheless, across the two languages, the scores for cumulative length of exposure are comparable for all three bilingual groups.

We calculated as correct responses those in which the determiner and noun were both appropriately marked for each gender. The group results for all three genders are given in Table 4 .

Table 4

Greek: average percentage of Ns with target determiner

\begin{tabular}{l|ccccc}
\hline \multicolumn{1}{c|}{ Group } & $\mathrm{N}$ & Masculine & Feminine & Neuter \\
\hline \multirow{2}{*}{ L1 children } & \multirow{2}{*}{21} & 100 & 100 & 100 \\
& & $S D--$ & $S D--$ & $S D--$ \\
2L1 children & & 92.1 & 99.1 & 99.4 \\
& 19 & $S D 19.9$ & $S D 3.8$ & $S D 2.5$ \\
Early successive bilinguals & & & & 50.6 & 95.0 \\
& & & $S D 37.5$ & $S D 34.9$ & $S D 9.9$ \\
L2 children & & 29.4 & 35.7 & 80.4 \\
& 19 & $S D 27.9$ & $S D 28.9$ & $S D 23.7$ \\
\hline
\end{tabular}

The ESB and L2 groups had the highest performance in neuter, whereas the $2 \mathrm{~L} 1$ children were at ceiling with all genders. A within-group analysis (paired sample t-tests, with $\alpha$ adjusted to .025 using Bonferroni correction) showed that the ESB children performed better with feminine than masculine $(t(18)=-3.3, p<.025)$, and with neuter than both feminine $(t(18)=-5.5, p<.001)$ and masculine $(t(18)$ $=-6.6, p<.001)$. A similar pattern was found for L2 children: scores on feminine were significantly higher than masculine $(t(18)=-2.5, p<.01)$, and scores on neuter were significantly higher than both feminine $(t(18)=-6.3, p<.001)$ and masculine $(t(18)=-7.5, p<.001)$.

\footnotetext{
5 Similarly to the Dutch groups, children who had $0 \%$ exposure to Greek or 0 cumulative years of exposure were children who spoke English only at home, who attended an English-speaking school and whose main/only contact with Greek was during a 2/3-hour class every week and from ambient language exposure, (i.e., in shops).
} 
A between-group analysis revealed a significant effect of group with masculine nouns $(F(3,74)=$ $41.5, p<.001)$, feminine nouns $(F(3,74)=42.5, p<.001)$ and neuter nouns $(F(3,74)=9.9, p<.001)$. Post-hoc comparisons (Tukey) showed that the ESB and L2 groups were significantly different from the $2 \mathrm{~L} 1$ and the $\mathrm{L} 1$ group with masculine (2L1 vs. ESB, $M D=60.0, p<.001 ; 2 \mathrm{~L} 1 \mathrm{vs}$. L2, $M D=62.7$, $p<.001$; L1 vs. ESB, $M D=62.9, p<.001$ and L1 vs. L2, $M D=70.6, p<.001)$ and feminine nouns (2L1 vs. ESB, $M D=48.5, p<.001 ; 2 \mathrm{~L} 1$ vs. L2, $M D=63.4, p<.001$; L1 vs. ESB, $M D=49.4, p<$ .001 and L1 vs. L2, $M D=64.3, p<.001)$. In the case of neuter nouns, however, the L2 group was significantly different from the L1 $(M D=19.6, p<.001), 2 \mathrm{~L} 1(M D=19.0, p<.001)$ and ESB $(M D=$ $14.6, p<.001)$ groups.

As with the Dutch data, simple bivariate correlations between independent and dependent variables were first carried out and those independent variables with significant correlations were entered into the relevant regression analysis. The Greek data exhibit high multicollinearity among the independent variables, that is, the predictor variables are highly correlated and consequently, following Jia et. al. (2002: 619, fn. 4), a backward-elimination method was used to eliminate all variables that did not add significant predictive power to the combination of the other variables. The following variables were entered for all three genders: age of onset, age at time of testing, cumulative length of exposure, $\%$ exposure to Greek, and vocabulary score in Greek (DVIQ-GR). For masculine nouns (adjusted $R^{2}=$ $.46 ; F(2,54)=25.1, p<.001)$ the results show that \% exposure to Greek $(\beta=.47, p=.001)$ and vocabulary score $(\beta=.30, p<.05)$ were the only significant predictor variables. The same holds for feminine nouns (adjusted $R^{2}=.54 ; F(2,54)=34.1, p<.001$ ) (\% exposure to Greek: $\beta=.49, p<.001$; vocabulary score: $\beta=.34, p<.01$ ). and for both these genders, $\%$ exposure to Greek has a larger Beta coefficient, indicating that its effect on the children's accuracy scores is greatest. For neuter nouns (adjusted $\left.R^{2}=.35 ; F(1,55)=30.5, p<.001\right)$, vocabulary score $(\beta=.60, p=.001$ ) was the only significant predictor variable.

Similarly to the Dutch data, the relatively low numbers for cumulative length of exposure for the early successive bilingual $(M=2 ; 3)$ and the L2 children $(M=0 ; 6)$ groups mean that it is not possible to find simultaneous bilinguals with comparable cumulative lengths of exposure, since in that case the children would be too young to test using the same experimental tasks. We can, however, compare a subset of the 2L1children $(n=13)$ and the ESB children $(n=9)$ with an average of 2-4 years' cumulative exposure to Greek. The findings show that there was a significant difference between the two groups with masculine $(U=17.5, z=-2.9, \mathrm{p}<.01)$ and feminine $(U=13, z=-3.4, \mathrm{p}<.01)$ gender but not with neuter. More specifically, the $2 \mathrm{~L} 1$ children were significantly more accurate in their production of the target determiner with masculine and feminine nouns than the ESB children.

To summarize: the L1 and 2L1 children performed at ceiling in all three genders. All bilinguals performed better with neuter than masculine and feminine gender. With feminine and masculine nouns, the L1 and 2L1 groups were significantly different from the other two (ESB and L2) groups, whereas with neuter nouns, the only between-group difference was between the L2 children and each of the other three groups. Thus, these findings suggest that there may be an effect of age of onset, although this appears to be different for masculine and feminine, on the one hand, versus neuter, on the other. However, a regression analysis showed that it was the exposure-related variables which account for most variance with masculine and feminine nouns, with \% exposure to Greek and vocabulary score best predicting performance, where together they accounted for about half of the variance in children's accuracy scores. For neuter nouns, vocabulary score was the only significant predictor variable, accounting for almost two thirds of the variance in the children's accuracy scores.

\section{Discussion}

In this paper, we presented data from English/Dutch and English/Greek bilingual children in order to investigate the effect of age of onset and input quantity on the acquisition of grammatical gender as marked on definite determiners. Our first research question asked whether there was any evidence for age effects in early child bilingualism, and we hypothesised that if the proposal put forward by Meisel (2009) was correct, namely that the optimal age for the acquisition of some aspects of morphosyntax is before age 4, the linguistic development of children first exposed to the second language at or after this age should be different from that of children whose age of first exposure is before 4 . To this end, we 
divided children into three age groups based on their age of onset: $2 \mathrm{~L} 1$ children (i.e., children exposed to both languages from birth), early successive bilingual children (i.e., those exposed to the L2 between 1 and 4 years), and L2 children (i.e., children first exposed to the L2 from 4 to 10).

When it comes to the types of errors which children made, that is, a possible qualitative difference, the three age groups behaved similarly. In Dutch, children in all three bilingual groups overgeneralized de with neuter nouns, rather than het with common nouns, and there were no significant differences between the three groups of bilingual children. In Greek, children in all three bilingual groups overgeneralized the neuter definite determiner to with masculine and feminine nouns. However, the average rate of target-like production did differ between groups for Greek. The 2L1 children were at ceiling with all three genders. For masculine and feminine nouns, the $2 \mathrm{~L} 1$ children were significantly different from both the ESB and the L2 children, and for neuter nouns, the L2 children were significantly different from both of the other groups. The explanatory role of age of onset in the Greek data is, however, undermined by the regression results, in which this factor did not turn out to be a significant predictor variable for any gender.

What these results show, then, is that while the Greek data are suggestive of an age effect, the relevant age - if age is the crucial factor - should be much earlier than suggested, for instance, by Meisel (2009). Given that the significant difference for masculine and feminine nouns was between 2L1 children, on the one hand, and ESB and L2 children, on the other, the relevant age must lie somewhere between birth and around age 2, the difference between the age of onset for the 2L1 children and the average age of onset for the English/Greek early successive bilinguals. It is possible, however, that what is crucial here is not chronological age per se, but the existence of another developing linguistic system. In other words, an important difference between these two groups of children - clearly related to chronological age, yet crucially distinct - is the fact that the early successive bilingual children already had (at least) part of their L1 system in place when exposure to the L2 first took place, and as such, their L2 developmental path had a potentially different starting point. More specifically, whereas the 2L1 children acquiring English and Greek from birth would have learned to use gender to classify nouns from the start, this may not have been the case for (some of) the early successive bilingual children, who, when first exposed to Greek, already had a developing linguistic system which did not use gender as part of noun classification.

The observation that age of onset appears to play no or little role in the acquisition of gendermarking on definite determiners in Dutch may in fact be expected given that it is typically acquired late by monolingual children. In Section 4, we noted that previous literature on the L1 acquisition of grammatical gender in Greek and Dutch had shown that this takes longer for Dutch than for Greek. This cross-linguistic difference was also reflected in the results of the present study for the simultaneous bilingual children. Despite more or less comparable ages at time of testing (an average of 5;5 for the English/Greek children and 5;11 for the English/Dutch children), the 2L1 English/Greek children were at ceiling with all three genders, whereas the 2L1 English/Dutch still performed rather poorly with neuter gender $(M 36.3 \%)$. In both language samples, though, the $2 \mathrm{~L} 1$ children did not differ significantly from the L1 children. It is possible that Meisel's (2009) proposal, which claims that the optimal age for some aspects of (second) language acquisition is before age 4, is simply not relevant to target language properties which are acquired at or after this age. Of course, this raises the interesting and non-trivial question of what it means for a child to have acquired a given linguistic property, and whether for example, emergence (e.g., first productive occurrence) or mastery (e.g., 90\% correct in obligatory contexts) criteria should be used. If we were to take mastery as the relevant criterion, then target-like production of the neuter determiner het is clearly only in place well beyond age 4. However, if we are to adopt a criterion based on emergence, this particular property of Dutch can be used to test Meisel's approach, because even though production of het is far from target-like, there were 4-year-old children who (sometimes) produced het with neuter nouns. For example, in the monolingual data presented in Section 6, the six 4 year olds produced het with neuter nouns at an average rate of $34.5 \%$ (SD 24.6\%). Crucially, their use of het was restricted to neuter nouns, suggesting they were using it to mark grammatical gender. More generally, whether age of onset effects should be expected for target language properties which are late-acquired in monolingual L1 acquisition may depend on the property in question, and whether for example, this property is dependent on some earlier acquired knowledge or on the acquisition of more sophisticated processing 
abilities, neither of which seem to be the case in the acquisition of Dutch gender (see Unsworth et al., in press, for relevant discussion).

Irrespective of the potential role of age of onset, in both sets of data, there was a confound between age of onset and input quantity (see also Flege, 2009, for relevant discussion). In the present study, input quantity was operationalized using a new measure, cumulative length of exposure, which involved taking into account the degree of exposure to the target language over time when calculating length of exposure. When Dutch early successive bilingual and L2 children were matched on this measure, they were found to pattern similarly. In contrast, when Greek $2 \mathrm{~L} 1$ and early successive bilingual children were similarly matched, the age effect appeared to remain. However, it should be noted that most of the children in the early successive group had an inconsistent exposure pattern: while their initial exposure to Greek had been between 1 and 4 years, usually at a Greek-language nursery or pre-school, this exposure had not been maintained over time. In other words, the intensity of their exposure differed from that of the $2 \mathrm{~L} 1$ children in terms of consistency as well as frequency. For feminine and masculine, this raises two possibilities: the amount of input necessary for consolidating nouns as feminine or masculine would be compromised, or there is both an effect of age of onset and amount of exposure. For neuter, on the other hand, strong input effects may not be expected because this is the default gender, and hence, a disruption in exposure should not affect performance. In order to make a more reliable comparison between the various age groups, it would be necessary to locate early successive bilingual English/Greek children whose exposure patterns in the early years were more regular, and for both languages, it would be desirable to include L2 children with a longer cumulative length of exposure and $2 \mathrm{~L} 1$ children who were younger at time of testing (bearing in mind the practical issue outlined above, however). Thus, while our attempts to match children based on cumulative length of exposure suggest that the age effects may in fact be input effects in disguise, we acknowledge that the limited sample size must moderate our conclusion.

More generally, the results for cumulative length of exposure reveal an enormous amount of variation both between and within groups. Some of this variation reflects the natural variation which is part and parcel of the linguistic environment of children growing up with two languages, irrespective of the exact constellation in which these two languages occur, but part of it will also be the consequence of the situation specific to certain groups. The data presented here indicate that when attempting to determine the role of age of onset in (early) L2 acquisition, and more specifically, when making claims about age of onset as the crucial variable differentiating the linguistic development of certain groups, it is vital that input quantity is also controlled for, insofar as possible. Furthermore, using the traditional way of measuring length of exposure (i.e., chronological age minus age of onset) may not be detailed enough to do this (see Unsworth, 2011, for further discussion).

Our second research question asked whether there are input effects in early child bilingualism. More specifically, we predicted that the acquisition of grammatical gender in Dutch by bilingual children would be affected by the amount of input to which children are exposed, and that this in principle would hold for grammatical gender in Greek, too, but to a lesser extent. We determined whether there were input effects by conducting a regression analysis on the two sets of data. For Dutch, the final model (for neuter nouns only) included chronological age, vocabulary, and cumulative length of exposure as significant predictor variables, with the latter accounting for the most variance, and \% exposure to Dutch approaching significance. For Greek, \% exposure to Greek was a significant predictor variable for children's responses on masculine and feminine nouns, as well as vocabulary score, and for neuter nouns, vocabulary score was the only significant predictor variable. With the exception of neuter nouns in Greek, these results show that the amount of input to which children are exposed (at the present moment) is, followed by vocabulary score, the best predictor for bilingual children's acquisition of grammatical gender in both languages. The adjusted $R^{2}$ values are comparable for Dutch and for Greek (.55, cf. .46 and .54), suggesting that together, the predictor variables account for about the same amount of variance in both languages. Furthermore, examining the Beta coefficients for the exposure-related variables only (i.e., cumulative length of exposure and $\%$ current exposure), we find that they are comparable for Dutch (cumulative length of exposure: $\beta=.45$ ) and for Greek (\% exposure: $\beta=.47$ for masculine and .49 for feminine). It thus appears that, at least when we compare the two languages in this way, the amount of input to which children are exposed does not appear to play a greater role in the acquisition of grammatical gender by English/Dutch children than 
by English/Greek children. This is unexpected given the differences in how gender is instantiated in the two systems, that is, whereas gender in Greek is rather transparent, in Dutch it is much more opaque.

There are a number of issues here. First, comparing Beta coefficients may not be the most accurate way of determining the relative contribution of the various input-related variables in the two sets of data; more sophisticated statistical procedures may be necessary. Second, it should be noted that the input-related variables which are significant predictor variables differ between the two languages (i.e., while cumulative length of exposure accounts for most variance in the English/Dutch data, for the English/Greek data, this is \% of exposure). In this regard, it is informative to consider how these two variables differ and how they overlap. Cumulative length of exposure in part encompasses \% exposure to Greek/Dutch in that it includes children's exposure to Greek/Dutch from birth up to and including the present moment; however, the \% exposure to Greek/Dutch measure is more detailed in that includes more sources of language input than home (parents) and daycare/school. In this sense, then, it may be the case that it is amount of input over time which has a greater effect on the acquisition of gender in Dutch than the acquisition of gender in Greek (Gathercole \& Thomas, 2009; Unsworth, under review). It is nevertheless also important to bear in mind that \% exposure to Greek may turn out to be a more significant predictor variable simply because this is the independent variable which includes the most variance in the sample of children tested here. Finally, it should be acknowledged that the differences in number of participants and in the ranges of the relevant independent variables make a completely accurate comparison of the two data sets is difficult. In future research, it may be possible to take children from the larger Dutch sample and match them on a case-by-case basis on the relevant independent variables with the children in the smaller Greek sample.

The tasks employed here targeted gender-marking on definite determiners only, which - for Dutch at least - may be taken as an indicator of children's knowledge of gender attribution. Given that the Dutch-acquiring child has to more or less attribute gender to nouns on a word-by-word basis, this is exactly where input effects are to be expected. When it comes to gender agreement, for instance, between the noun and an adjective, it is possible that the amount of input a child hears is less important. Assuming that gender agreement is a purely syntactic phenomenon, then - from a generativist perspective at least - it should not be subject to input effects, at least not to the same extent (but cf. Blom et al., 2008). We leave the question of whether this is the case to future research.

For Dutch, our focus has almost exclusively been on the results for neuter nouns. For common nouns, all three groups of bilingual children were found to perform at ceiling. It is important to note that this target-like production of the definite determiner de may not in fact reflect underlying targetlike knowledge of common gender, that is, $d e$ may be used as a default value for definiteness rather than for gender (Cornips \& Hulk, 2008). In this sense, then, the target-like performance of the bilingual children for Dutch common nouns may not be comparable with the target-like performance of the bilingual children in Greek. One further possible difference between the two languages may be the way in which gender is acquired. Given the differences in the target system, as illustrated above, it is possible that the developmental paths for the two languages may be different: whereas the acquisition of grammatical gender in Dutch in part involves lexical acquisition, the acquisition of grammatical gender in Greek appears to involve syntactic agreement from the early stages. Again, we will explore this possibility in future work.

\section{Conclusion}

The data analysed in the present paper suggest a complex interplay between the factors of input quantity and age of onset. This may hold not only for how these two factors interact in the linguistic development of bilingual children, thereby suggesting that an approach such as Meisel (2009) is too global, but also for how researchers go about comparing the linguistic development of different types of bilingual children. Furthermore, investigating the acquisition of the same target language property by the same types of bilingual children in two different target languages, allowed us to pinpoint the crucial aspects of that property and examine more thoroughly how it relates to the bilingual children's background variables. 


\section{References}

Barreña, Andoni, Ezeizabarrena, Marie-José, \& García, Iñaki. (2008). Influence of the linguistic environment on the development of the lexicon and grammar of Basque bilingual children. In Carmen Pérez-Vidal, Maria Juan-Garau, \& Aurora Bel (Eds.), A portrait of the young in the new multilingual Spain (pp. 86-110). Clevedon, UK: Multilingual Matters.

Blom, Elma, Polišenskà, Daniela, \& Weerman, Fred. (2008). Articles, adjectives and age of onset: The acquisition of Dutch grammatical gender. Second Language Research, 24, 297-332.

Carroll, Susanne E. (1989). Second-language acquisition and the computational paradigm. Language Learning, $39,535-594$.

Chilla, Solveig. (2008). Erstesprache, Zweitsprache, spezifische Sprachentwicklungsstörung? Eine Untersuchung des Erwerbs der deutschen Hauptsatzstruktur durch sukzessiv-bilinguale Kinder mit Türkischer Erstsprache. Doctoral dissertation, Hamburg University.

Cobo-Lewis, Alan B., Pearson, Barbara Z., Eilers, Rebecca E., \& Umbel, Vivian C. (2002a). Effects of bilingualism and bilingual education on oral and written Spanish skills: A multifactor study of standardized test outcomes. In D. Kimbrough Oller, \& Rebecca E. Eilers (Eds.), Language and literacy in bilingual children (pp. 98-117). Clevedon, UK: Multilingual Matters.

Cobo-Lewis, Alan B., Pearson, Barbara Z., Eilers, Rebecca E., \& Umbel, Vivian C. (2002b). Effects of bilingualism and bilingual education on oral and written English skills: A multifactor study of standardized test outcomes. In D. Kimbrough Oller, \& Rebecca E. Eilers (Eds.), Language and literacy in bilingual children (pp. 64-97). Clevedon, UK: Multilingual Matters.

Cornips, Leonie, \& Hulk, Aafke. (2008). Factors of success and failure in the acquisition of grammatical gender in Dutch. Second Language Research, 28, 267-296.

De Houwer, Annick. (1990). The acquisition of two languages from birth: A case study. Cambridge: Cambridge University Press.

De Houwer, Annick. (2007). Parental language input patterns and children's bilingual use. Applied Psycholinguistics, 28, 411-424.

Donaldson, Brian C. (1987). Dutch reference grammar. Leiden: Martinus Nijhoff.

Dunn, Lloyd M., Dunn, Leota M., \& Schlichting, Liesbeth. (2005). Peabody picture vocabulary test-III-NL. Amsterdam, The Netherlands: Pearson.

Dunn, Lloyd M., \& Dunn, Douglas M. (2007). Peabody picture vocabulary test (PPVT-4) (Fourth Edition ed.). Minneapolis, USA: Pearson.

Dunn, Lloyd M., Dunn, Leota M., Whetton, Chris, \& Burley, Juliet. (1997). The British picture vocabulary scale. London, UK: GL Assessment.

Flege, James E. (2009). Give input a chance! In T. Piske \& M. Young-Scholten (Eds.), Input matters in SLA (pp. 175-190). Clevedon, UK: Multilingual Matters.

Franceschina, Florencia. (2005). Fossilised second language grammars. the acquisition of grammatical gender. Amsterdam: John Benjamins.

Gathercole, Virginia C. M. (2002a). Command of the mass/count distinction in bilingual and monolingual children: An English morphosyntactic distinction. In D. Kimbrough Oller, \& Rebecca E. Eilers (Eds.), Language and literacy in bilingual children (pp. 175-206). Clevedon: Multilingual Matters.

Gathercole, Virginia C. M. (2002b). Grammatical gender in bilingual and monolingual children: A Spanish morphosyntactic distinction. In D. Kimbrough Oller, \& Rebecca E. Eilers (Eds.), Language and literacy in bilingual children (pp. 207-219). Clevedon: Multilingual Matters.

Gathercole, Virginia C. M. (2002c). Monolingual and bilingual acquisition: Learning different treatments of thattrace phenomena in English and Spanish. In D. Kimbrough Oller, \& Rebecca E. Eilers (Eds.), Language and literacy in bilingual children (pp. 220-254). Clevedon: Multilingual Matters.

Gathercole, Virginia C. M., \& Thomas, Enlli M. (2005). Minority language survival: Input factors influencing the acquisition of Welsh. In James Cohen, Kara T. McAlister, Kellie Rolstad, \& Jeff MacSwan (Eds.), Proceedings of the 4th international symposium on bilingualism (pp. 852-874). Somerville, MA: Cascadilla Press.

Genesee, Fred, \& Nicoladis, Elena. (2007). Bilingual first language acquisition. In Erika Hoff, \& Peggy McCardle (Eds.), Handbook of language development (pp. 324-342). Oxford, UK: Blackwell.

Gilger, Jeffrey W. (1992). Using self-report and parental-report survey data to assess past and present academic achievement of adults and children. Journal of Applied Development Psychology, 13, 235-256.

Granfeldt, Jonas, Schlyter, Suzanne, \& Kihlstedt, Maria. (2007). French as cL2, 2L1 and L1 in pre-school children. PERLES: Petites Études Romanes De Lund, 21, 6-43. 
Gutiérrez-Clellen, Vera F., \& Kreiter, Jacqueline. (2003). Understanding child bilingual acquisition using parent and teacher reports. Applied Psycholinguistics, 24, 267-288.

Haeseryn, Walter. (1997). Algemene nederlandse spraakkunst. Groningen: Martinus Nijhoff.

Herschensohn, Julia R. (2007). Language development and age. Cambridge: Cambridge University Press.

Hoff, Erika. (2006). How social contexts support and shape language development. Developmental Review, 26, 55-88.

Hulk, Aafke, \& Roodenburg, Jasper. (2008). Puzzles on grammatical gender. Lingue e Linguaggio, VII, 67-91.

Hulk, Aafke, \& Cornips, Leonie. (2006). The acquisition of definite determiners in child L2 Dutch: Problems with neuter gender nouns. In Sharon Unsworth, Teresa Parodi, Antonella Sorace, \& Martha Young-Scholten (Eds.), Paths of development in L1 and L2 acquisition (pp. 107-134). Amsterdam: John Benjamins.

Hurtado, Nereyda, Grüter, Theres, Marchman, Virginia, \& Fernald, Aanne. (2009). Are bilingual toddlers slower than monolinguals in real-time processing of spoken language? Poster presented at ISB7, Utrecht University.

Hyltenstam, Kenneth. (1992). Non-native features of near-native speakers. In Richard J. Harris (Ed.), Cognitive processes in bilinguals (pp. 351-368). Amsterdam: North Holland.

Jia, Gisela, \& Aaronson, Doris. (2003). A longitudinal study of Chinese children and adolescents leaning English in the United States. Applied Psycholinguistics, 24, 131-161.

Jia, Gisela, Aaronson, Doris, \& Wu, Y. (2002). Long-term language attainment of bilingual immigrants: Predictive variables and language group differences. Applied Psycholinguistics, 23, 599-621.

Kupisch, Tanja, Müller, Natascha, \& Cantone, Katja F. (2002). Gender in monolingual and bilingual first language acquisition. Lingue e Linguaggio, 1, 107-150.

Marchman, Virginia, Martinez-Sussman, Carmen, \& Dale, Philip S. (2004). The language-specific nature of grammatical development: Evidence from bilingual language learners. Developmental Science, 7, 212-224.

Mastropavlou, Maria. (2006). The role of phonological salience and feature interpretability in the grammar of typically developing and language impaired children. Unpublished Doctoral dissertation, Aristotle University of Thessaloniki.

Mastropavlou, Maria, \& Tsimpli, Iianthi M. (2011). The role of suffixes in grammatical gender assignment in Modern Greek: A psycholinguistic study. Journal of Greek Linguistics, 11, 27-55.

McDonald, Janet L. (2000). Grammaticality judgments in a second language: Influences of age of acquisition and native language. Applied Psycholinguistics, 21, 395-423.

Meisel, Jürgen M. (2009). Second language acquisition in early childhood. Zeitschrift Für Sprachwissenschaft, 28, 5-34.

Montrul, Silvina A., Foote, Rebecca, \& Perpiñán, Silvia. (2008). Gender agreement in adult second language learners and Spanish heritage speakers: The effects of age and context of acquisition. Language Learning, 58, 503-553.

Müller, Natascha. (1990). Developing two gender assignment systems simultaneously. In Jurgen M. Meisel (Ed.), Two first languages: Early grammatical development in bilingual children (pp. 194-243). Dordrecht, The Netherlands: Foris.

Paradis, Johanne, Emmerzael, Kristyn, \& Duncan, Tamara S. (2010). Assessment of English language learners: Using parent report on first language development. Journal of Communication Disorders, 43, 474-497.

Paradis, Johanne, \& Genesee, Fred. (1996). Syntactic acquisition in bilingual children: Autonomous or independent? Studies in Second Language Acquisition, 18, 1-25.

Rodriguez, Eileen T., Tamis-LeMonda, Catherine S., Spellman, Mark E., Pan, Barbara A., Raikes, Helen, LugoGil, Julieta, \& Luze, Gale. (2009). The formative role of home literacy experiences across the first three years of life in children from low-income families. Journal of Applied Development Psychology, 30, 677-694.

Rothweiler, Monika. (2006). The acquisition of V2 and subordinate clauses in early successive acquisition of German. In Conxita Lleó (Ed.), Interfaces in multilingualism: Acquisition, representation and processing (pp. 93-115). Amsterdam: John Benjamins.

Sabourin, Laura, Stowe, Laurie A., \& de Haan, Ger J. (2006). Transfer effects in learning a second language grammatical gender system. Second Language Research, 22, 1-29.

Scheele, Anna F., Leseman, Paul P. M., \& Mayo, Aziza Y. (2010). The home language environment of monolingual and bilingual children and their language proficiency. Applied Psycholinguistics, 31, 117-140.

Stavrakaki, Stavroula, \& Tsimpli, Ianthi M. (2000). Diagnostic verbal IQ test for school and preschool children: Standardization, statistical analysis, and psychometric properties. In Proceedings of the 8th conference of the panhellenic association of speech and language therapists (pp. 95-106). Athens: Ellinika Grammata.

Stephany, Ursula. (1995). The acquisition of Greek. Köln, Germany: Institut für Sprachwissenschaft Universität zu Köln. 
Thordardottir, Elin. (2008). Relationship between amount of language exposure and language scores in older preschool children acquiring french and english simultaneously. Paper presented at IASCL, University of Edinburgh.

Tsimpli, Ianthi M. (2004). Features in L1 and L2 acquisition: Evidence from Greek clitics and determiners. In Henriette Hendriks (Ed.), Analyse comparative des processus d'acquisition en L1 et L2 (Special Issue of AILE (Acquisition et Interaction en Langue Étrangère), $20^{\text {th }}$ ed., pp. 87-128)

Unsworth, Sharon. (2008). Age and input in the acquisition of grammatical gender in Dutch. Second Language Research, 24, 365-396.

Unsworth, Sharon. (2011). Utrecht bilingual language exposure calculator. Unpublished manuscript, available from author upon request.

Unsworth, Sharon. (under review). Assessing the role of amount and type of exposure in simultaneous bilingual acquisition: The case of Dutch gender.

Unsworth, Sharon, Argyri, Froso, Cornips, Leonie, Hulk, Aafke, Sorace, Antonella, \& Tsimpli, Ianthi. (in press). Bilingual acquisition of Greek voice morphology and Dutch gender: What do they have in common? Proceedings of Boston University Conference on Language Development.

Unsworth, Sharon, \& Hulk, Aafke. (2009). L1 acquisition of neuter gender in Dutch: Production and judgement. Proceedings of Generative Approaches to Language Acquisition 2009.

Valian, Virginia. (1999). Input and language acquisition. In William B. Ritchie, \& Tej J. Bhatia (Eds.), Handbook of child language acquisition (pp. 497-527). San Diego, CA: Academic Press.

Van Berkum, Jos J. A. (1996). The psycholinguistics of grammatical gender: Studies in language comprehension and production. Doctoral dissertation, Max Planck Institute for Psycholinguistics.

van der Velde, Marlies. (2003). Déterminants et pronoms en néerlandais et en français: Syntaxe en acquisition. Doctoral dissertation, Paris 8.

Varlokosta, Spyridoula. (1995). Greek as a second language in minority schools of thrace: Learning gender compared to learning number and case within the NP. Unpublished manuscript. 


\title{
Selected Proceedings of the 4th Conference on Generative Approaches to Language Acquisition North America (GALANA 2010)
}

edited by Mihaela Pirvulescu, María Cristina Cuervo, Ana T. Pérez-Leroux, Jeffrey Steele, and Nelleke Strik

\author{
Cascadilla Proceedings Project Somerville, MA 2011
}

\section{Copyright information}

Selected Proceedings of the 4th Conference on Generative Approaches

to Language Acquisition North America (GALANA 2010)

(C) 2011 Cascadilla Proceedings Project, Somerville, MA. All rights reserved

ISBN 978-1-57473-447-8 library binding

A copyright notice for each paper is located at the bottom of the first page of the paper. Reprints for course packs can be authorized by Cascadilla Proceedings Project.

\section{Ordering information}

Orders for the library binding edition are handled by Cascadilla Press.

To place an order, go to www.lingref.com or contact:

Cascadilla Press, P.O. Box 440355, Somerville, MA 02144, USA

phone: 1-617-776-2370, fax: 1-617-776-2271, sales@ cascadilla.com

\section{Web access and citation information}

This entire proceedings can also be viewed on the web at www.lingref.com. Each paper has a unique document \# which can be added to citations to facilitate access. The document \# should not replace the full citation.

This paper can be cited as:

Unsworth, Sharon, Froso Argyri, Leonie Cornips, Aafke Hulk, Antonella Sorace, and Ianthi Tsimpli. 2011. On the Role of Age of Onset and Input in Early Child Bilingualism in Greek and Dutch. In Selected Proceedings of the 4th Conference on Generative Approaches to Language Acquisition North America (GALANA 2010), ed. Mihaela Pirvulescu et al., 249-265. Somerville, MA: Cascadilla Proceedings Project. www.lingref.com, document \#2600. 